\title{
Research on English Language Teaching Practice in Open Distance Learning
}

\author{
Yingling $\mathrm{Gu}$ \\ Xinjiang Changji Radio and TV University \\ Changji 831100, Xinjiang, China \\ E-mail: gylroom@sina.cn
}

\begin{abstract}
A new stage of development for modern distance education has been entered in China. The main signs are: One of the main tasks is a Plan of Action for the revitalization on modern distance education project as the 21st century education; the project of open educational pilot has been implemented by all Radio \& TV University systems. Under such an educational situation, modern distance education pilot project developed in the English undergraduate students, in March 2000 in Changji. With the guidance of CCTV and Changji People's Government, 42 of undergraduate English students were recruited at the same year in August, the school began in September. Under the modern distance educational conditions, Teachers of TVU how to teach? Students how to learn? A variety of media technology how to combine the application? Distance learning how to improve the system of support services? And so on, new problems need to be recognized and explored by the TVU educators of the long-distance educational practice for decades. Practice is needed for theoretical guidance, theory is also needed to enrich in the practice of refining. According to the combination of experimental work, Xinjiang Changji TVU is led by the Ministry of Education in Xinjiang Institute of Research Group, research and experiment of English teaching mode is being carried out.
\end{abstract}

Keywords: Open distance learning, Teaching practice, Mode, Research

\section{Introduction}

\subsection{Research on objective}

The topics mainly access the theoretical analysis of Distance Open Educational mode, and Changji Radio and TV University turned out the trial English Teaching in English major in 2000, teachers applied a variety of media means and students taught by themselves, such as independent study, explore the principles of open education, distance education with modern characteristics of a new teaching model.

To improve the quality of modern distance education, and promote the educational reform of TVU, which develops Xinjiang Changji's modern distance education in healthily and rapidly.

\subsection{Research on Methods}

The main topic will be adopted the comprehensive integration of research methods in theoretical research and empirical analysis, including literature of research, follow-up survey questionnaire, visiting a forum and practical contrast and so on, according to the Plan, researcher completed the separate report and total report.

\subsection{Results of research}

Maybe the results of the major topics are:

1). The study report: "the practice and innovation of English Language Teaching mode in Open Distance Education".

2). The one of the investigated report: "the content, features and main links of English Teaching in Distance Education".

3). The two of reports: "the study of teaching and learning in English students in Changji Xinjiang Radio and Television University investigated in 2000."

4). The three of reports: "the analysis of the survey on Changji Radio and TV University undergraduate trainees self-study."

5). The four of reports: "the multimedia services of Grant explore in TVU Open and Distance Learning." 


\section{Theoretical Analysis of English Teaching Model in Distance Education}

\subsection{The connotation of English teaching in distance education}

Teaching process is inclusive of any teachers, students, teaching information, teaching methods and other basic elements. The flow of information and processing with teaching, these basic elements display their respective position itself and play a certain role. They are not co-exist in isolation for the process of teaching, but insisted of interacting an organic whole, it has some stable forms of structure. This is Changji Radio and TVU to develop the teaching mode. A reasonable mode of teaching is to create a good learning environment. The best educational teaching methods will be organized for learning of students and for teaching of teachers, it guides teaching objectives and promotes the development of students.

The traditional teaching is a teacher-centred, It emphasizes the teachers are leading role and dominant role during the process of teaching. Teachers teach students any information through explaining in detail, students are made to receive the teaching information, they are accepted the external environment, the teaching information is educated to the students by teachers, yet teaching methods and skills belong to the teachers. The basic elements of the teaching process is combined with the function of this structure, Practice has been proved that traditional teaching mode is trained most of the people who belong to the knowledge and talents, which is difficult to adapt the growing diversity of modern society and change rapidly..

Faced development trend of education reform, various tertiary institutions are committed to reform teaching and building a new teaching model. Especially Changji, faced severe tests, if not, development of modern distance learning will affect future rapid development, under this teaching situation of environment, Changji is a long-range development of education in the practice of teaching and learning, through constant exploration, basically established the modern teaching model of distance education. Six guides, that is "guiding fashion, guiding course, guiding means, guiding procedure, guiding technique and guiding resource".

Four studies, they are "individual study, collaborating study, collecting study, online study." Two actions (face to face, teacher and students, students and students, answer and reply or learn from one another).

According to this kind of teaching methods, "students used as the main roles, teacher used as guider or helper, resource is core and services are key", the course regarded as unit, based on the character of the course, the learners' quality, the condition of resource, guidance first, then using media necessarily, finally importance of outstanding, solving the difficult point; motivating students' interest, developing students' abilities; combining the explaining and practicing, stressing the effect. Exploring the teaching principle of one in three, with the teaching model of Xinjiang Radio and TVU four elements. based on the course, Classifying teaching and guidance. Everything sets out from practice, the main thing is man, the learners' demands are driven, extension and expansion of classroom space. The tutor stresses three points of the course (knowledge Point, difficult point and important point)when tutorials are beginning, paying much attention to summing up the knowledge, explaining the difficult and important points, yet guiding the way of studying, through practicing and understanding in time, deep memory, strengthening knowledge and ensuring the quality of teaching.

The main body is students. This seems to have a self-evident in theory. But because of the effect of factors during teaching practice, it is not so simple for students to show off really in class. Teaching activities are mainly through a variety of media in distance education, in which teaching and learning activities, students and teachers are often remote, isolated teaching time and space, students mainly learn something by yourselves, supported by the necessary counseling, providing teaching of information between the two-way feedback and thoughtful teaching services are through educational institutions or systems, to ensure that students have purposes, plans and orders to learn. Tutors should make full use of distance education system, mobilizing the enthusiasm of the students so that students can do them independently, it is beneficial for students to study as possible as, self-learning in the curriculum and teaching arrangements in the English Teaching of TV University.

The practice of the undergraduate is open educational English teaching and learners are on the observation in Changji TV University, the group of subjects think that RTVU English teaching, first of all we must design each lesson carefully, because the textbooks of TVU are larger in content, less face-to-face class, the requirements of in- class are high, the overall effect of listening, speaking, reading and writing set out from a certain way of teaching, integrating the purpose of teaching, content of teaching, approaches of teaching, teaching methods, means of teaching organically, supporting each other, so as to achieve teaching purposes. Any subject can not be separated from the steps of teaching, but English teaching is in the "five-step teaching" that is (Revision, Presentation, Drill, Practice, consolidation of practice) (Consolidation).To complete the task of teaching better, improving the quality of teaching, the specific approach is to strengthen the teaching effect of 50 minutes. 


\subsection{Prepare lessons seriously}

Firstly, Tutors must change the concepts. Based on the requirements of TVU materials. English teaching is not merely knowledge, but effectively organized various activities, a variety of media, to students practicing and using language. Creating a class emotional atmosphere is between teachers and students, students and students, exchanging ideas in English, the special atmosphere is being created in teaching and learning environment, we try to increase students' ability to use knowledge through the appropriate forum for training, so as to make it complex, continuous and natural, then students get to the languages. Secondly, preparing lessons, we should think what good teaching forms in advance, ready to do the necessary preparations before the class, making good use of media resources, holding various forms of interactive activities, such as classroom discussions, group activities. This will ensure that classroom teaching is high-density and fast-paced manner. Preparing lessons are not only teaching materials, but at the same time we have to consider the actual situation of students, the focus of teaching content, difficulty, teaching methods and means, and the steps of teaching.

\subsection{Strictly observed the "five-step teaching"}

The principle and made full use of classroom and 50 minutes. Grasped of time allocation principles: step one led to the new lesson (three minutes);step two given the question, discussed (IN PAIRS OR GROUPS)(5minutes).step three watched slides, to write "a topic of conversation" and then do exercises(15 minutes);step four watched a live lesson (12); step five used the application of new knowledge, teachers and students began to do some activities, the layout operations (communicate with each other) (15 minutes) all the necessary steps are in accordance with each class needs. It is necessary to intensify 50 minutes "concentration" The following are:

\subsubsection{Guiding model and guiding courses}

In terms of TVU students how to lead to the text effectively, and made students study as soon as possible. This has been exploring the subject. In the years of teaching practice, the way of teacher chosen is beginning with a story, the main line of per unit of the "title", so the students speak to each one, the story will be continued, such as:

Taking English at leisure, unit 6 as an example: everyone is familiar with the text "travel, before learning texts, the question raised:" Have you ever been to Beijing, what do you think of your travelling? "The problem is very simple. Also familiar with the theme, so students learn the high enthusiasm, and have started their own association. Almost everyone involved in, and without duplication. Although time is short, the show is only on the majority of students thought, but has been able to Basically cover the contents of the texts. Achieved good results.

\subsubsection{Guiding means}

Speaking of classroom teaching, people will think of such a teaching mode: Review -led new courses -taught new lesson- practice - layout assignment. Understandable, this mode of teaching has its use of certain reasonable. But you will find that students are passive, the lack of vibrant classroom, students lack vitality. Taking is:

\subsubsection{Establishing a new brain map.}

Practice has been proved that in the normal classroom teaching, trying to maximize the students to use more than one sense of the learning process, bearing information as far as possible through the sense. Records do not allow students, but following the teachers together with drawing the brain map of the entire structure of the tree.

\subsubsection{The creation of more than one format}

According to the characteristics of TVU teaching, allowing students to take the eyes, ears, mouth, hands and use of new teaching methods of teaching to do a new design. Construction of a "scenario - lead - use of" one of a number of foreign language teaching model that is (SGU (Sight Guide Usage) (watching slides and making full use of teaching media) people think that training Communicative competence should be the language skills for training services.

\subsubsection{Guiding process}

Teaching activities of the process, teachers lead students to understand the world, to know themselves, and constantly enrich themselves, to improve their process. In this process, students are active and continuous development of the main body. Teaching is the success of Central, Central, "deduction", to firmly grasp the hearts of students, to try to develop the world of the students, so that students in the classroom pay much more attention, concentrate on. To achieve this, the students must insist on the "four studies"(individual learning, collaborative learning, focus on learning, on-line learning); it is essential for long-distance learners to master the 
teaching. Because the foreign language teaching should be student-centered, students are internal and external causes through the internal functioning. As a foreign language teacher, finding ways to get students through the eyes, ears, hands, brain and other organs of the activities of access to knowledge, arouse the desire of students to acquire new knowledge, strengthen their motivation to learn. For example, in the classroom, before a few minutes, basically can be called "two-interaction" (teacher-student, students and students). Human language communication is the main form of dialogue. Therefore, to avoid teaching in the Tianya Shi, such as the use of attention to the form of questions and answers, group activities, pairs, teachers and students form of dialogue, two-way exchanges between the students. This series of activities are all in English dialogue. Teachers make full use of students to participate in some activities, combined the teaching of English listening and speaking exercises naturally into the classroom, the students improve the abilities with pleasure and consolidated the knowledge what they learned. During the tutorial, the activities of students are more, however, going over the old knowledge, or leading to the new courses, or understanding the new knowledge and exercise, stressed the system of structure integrity. The main line kept from beginning to the end. From the mobilization of students to participate in activities of speaking, every link has all students' activities, activities for students. Because the teachers would raise questions in every link, please be ready to answer any of the students, as long as someone is absent mind in class, not to concentrate on classes, you may answer mistakes, feel embarrassed. In order to avoid errors in the class, students access the new knowledge with the teacher explaining fast.

\section{Guiding technique, guiding resources--- emphasis on the use of media}

Before classroom teaching activities, students are only passively involved in teaching and learning activities. Their language ability and thinking ability have not improved, in particular, TVU adult education, English language proficiency of students is relatively low, in view of this situation, Changji TVU is established a strict evaluation mechanism, developed a series of strict and reasonable assessment methods, as a tutor, have to form a good habit of using modern distance education technology and multimedia resources. In such a request, increasing some audio-video classes, studying online, BBS discussion and more assignments such as: English at leisure Unit6 Activity1-Activity4 the main part of about travel and holidays, information of schedules, make bookings, arrange accommodation in the awarding of this class, firstly, organized students to conduct an overall teaching (top-down), secondly, the text is divided into two parts face-to-face tutorial , (Two topics: Travel and Holidays), thirdly, courses will be combined to use the video, online teaching resources, courseware and the face to face at the same time . Practice results show that teachers use the multimedia teaching methods, students adapt to the TVU classroom teaching, to develop after-school self-study habits, thereby enhancing the efficiency of learning a better effect.

\section{Main links in the TVU Open and Distance Education Teaching}

Implementation of modern distance education mode of teaching in general should have the following main teaching:

\subsection{The basic link of guiding courses is the process of teaching English}

All learning guide for students independent study is provided by TVU Open and Distance Education, it is a related to schools, teachers, media learning resources and learning support services, and many other complex systems of engineering. Guiding is to make students the whole process of the independent study, it is also important foundation and safeguard for students to complete the task of studying. In this paper, curriculum guide is the first session in English Teaching of TVU Open and Distance. Guiding mainly refers to the process of learning support services by teachers, the content of the English courses for guiding is main learning attitude, learning methods of guiding, the use of multi-media learning resources, curriculum development and other learning programmes support services.

English courses for guiding the main purpose and role is to guide and help students effectively carry out individual self-study. Introduction of English courses are the important prerequisite and guarantee for independent study courses, giving full play the guiding role of courses, students can learn as quickly as possible courses of study requirements, learning resources and learning skills, to solve the students why study, in what, the practical problems of how to help students self-learning, learning task of completing the course and lay a sound foundation.

\subsection{The important part of the process is students self-study courses teaching English}

The mode of learning of Open and Distance Education is self-study, which is important, but also is a significant feature of TVU Open and Distance Education. At the same time, students self-study is not only a philosophy of education but a learning ability. What this paper said is the students independent study, it means the course of a 
link of TVU Open and Distance Education Teaching English, that is, students is under the teacher's guidance and management, the use of multimedia courses teaching resources and modern technology means of self-study, self-building courses knowledge, learning courses to achieve the goal of the process.

In the process of teaching English courses, students self-study session is a main role, highlighted the autonomy of student learning center. According to the students' own learning and learning needs, determine curriculum learning objectives, choose their own development requirements of the study, use of text materials, audio-visual materials, satellite TV, the Internet for self-study, self-management, self-strengthening, self-monitoring and evaluation. Students self-study session fully reflects the student's principal role. However, stressed the need to ensure that students are self-study aspect of the quality of learning, students learning centre in a prominent position at the same time, teachers can not be ignored management of the important role and curriculum guidance.

The guidance and management of students independent study links is an important content of English teaching, but also it is the important preconditions of students independent study.

Management is to ensure the quality of student self-study. Students study in the independent learning, students are the masters of learning, the dominant position of the students are fully reflected. However, the Student Learning is not equivalent to individual learning, self-learning is not equivalent to their own learning, free learning. Independent of whether students are learning effectiveness, whether or not depends not only on students with a high degree of sense of responsibility and self-control study and learning capacity, especially on English courses for teachers whether the guidance and management put in place. Therefore, the correct guidance of teachers and effective management are to ensure the quality of student self-study. Teachers should fully understand the process of self-study student, guidance and management is the importance and necessity of self-learning students, doing managers and promoters is the teacher's job, students will carry out independent study, which truly reflects TVU Open and Distance Education " Student-centered learning "teaching characteristics.

Requirements of English teachers are for students of self-study. In independent study session, teachers should focus on learning concepts, learning strategies and methods for students in independent study guide, and make specific demands: Firstly, enhance the sense of self-learning, improve self-study and self-control ability. Reasonable arrangements for self-study time, in accordance with the curriculum learning programmes from the planned and systematic way for self-study Secondly, learn to use a variety of media resources and learn to search for relevant learning resources, make full use of media resources for learning courses independent study. Thirdly, consciously on the e-learning schools in accordance with the relevant provisions of e-learning courses to complete the task of knowledge. Fourthly, problems will be met during studying in various forms in time to ask teachers. Fifthly, serious understanding of the content of teaching materials complete independence of operation. Sixth, participate in the study group, and seriously carry out collaborative learning activities.

Conscientiously carry out self-study session. This is a basic part of independent study, the significance of building elements completes the study, mainly rely on self-learning and participate in practical activities, teachers only play the counselling role. In the process of teaching, the primary task of teachers is to help students stimulate motivation, to enhance awareness of the main study, to design the learning objectives, to develop study plans, to cultivate self-study habits, to foster self-confidence, to rule out reliance on psychology, to master the self-control methods and learn to use the media. The print media is the core of self-study students, electronic media is supplemented by technology. This combination of learning media exist for a long time, which is suitable for the vast majority of students.

\subsection{The necessary part of the teaching process of face-to-face tutorial}

The self-study students is a notable characteristic of TV University Distance Education, but face-to-face tutorial is a still indispensable link in RTVU teaching, it has become a consensus administrators and teachers and students. The characteristics of the main problems are face-to-face counselling course: At first, face-to-face tutorial is provided a support services; later, the face-to-face counselling is not only "teach" knowledge, it is more important to "guide "the students how to learn knowledge; next, face-to-face counselling is no longer a system of imparting knowledge, class arrangements for scientific and flexibility; Finally, in teaching methods, teachers make full use of modern educational technology and multimedia teaching resources for face-to-face counselling, and the use of two or more media teaching; at last, closed cooperation with a variety of media resources and teaching materials based on the curriculum guidance for key and difficult to answer difficult problems; Expanded knowledge, strengthen the sense of innovation and focus on capacity-building.

Face-to-face counselling is to play a leading role in the classroom teaching, it is an important way of 
troubleshooting for students to contact teachers. Despite the multi-media teaching has many advantages and benefits, but the multimedia courseware in the questions and answers are predictable and programmable, it is impossible to fully meet the individual differences of students, multimedia courseware can never replace teachers, teachers and students face-to-face teaching and exchanges can make up for the lack of interaction multimedia teaching, it is an important complement to the multi-media teaching. Face-to-face counselling teaching is the ultimate embodiment of "student-centered learning", face-to-face counselling should not be ignored, and its role should not be diluted. Face-to-face counselling should fully understand the function and role, grasp the teaching strategies, which makes it better service for students self-study.

In English Teaching, teachers should be based on the nature of the teaching characteristics, adhere to the students as the center, improve the learning support services principle, and strive to improve the effect of English. Teaching has "four stresses" that focus on the difficult point, important point, the methods of thinking and the way of study. Analysis of materials, analysis of students, at the same time answering to the students when they met the difficult problems.

In English class, the teachers have to combine the curriculum of multimedia teaching resources. According to text materials, multi-media teaching resources and online teaching resources, such as different media features, reasonable arrangements for a variety of media in teaching and the use of the method of teaching at different stages, to provide students with a strong learning guide services. English at leisure such as Unit7 Activity1-Activity4 the main part of about travel and holidays, information of schedules, make bookings, arrange accommodation in the awarding of this class, first, organize students to conduct an overall teaching (top-down), the text is divided into two parts, (two topics: Travel and Holidays),then courses will be video, online teaching resources, courseware and organically combine at the same time. This teaching model is suitable for the TVU classroom teaching, it prompted the students to develop good habits in dependent learning, so as to enhance learning efficiency.

The teachers' good job is guiding the students, and inspire students to learn the initiative and enthusiasm, training students scientific way of thinking. Attention to guiding students complete the corresponding units of study, make full preparations for attending the counselling classes, so as to enhance the teaching effectiveness. Introduction of the course, tutors help students master the content of the courses, so that students learn the content of the curriculum better, and ultimately achieving master teaching requirements of the target. Such as the English at leisure, unti7, everyone is familiar with the text of the "travel", the writer raised the question: "Have you ever been to Shanghai, what do you think of your traveling?" Question is very simple, the theme is familiar, so students learn the high enthusiasm, and have started their own association. Almost everyone involved in, and without duplication. Although time is short, the show is only on the majority of students think, but can already see that it basically covers the contents of the texts, and achieved good results.

The face-to-face counselling hours reduced in the TVU Open and Distance Education Courses, thus, the teaching methods is particularly important. The writer thinks that the characteristics of teaching English is in accordance with courses, the guiding principles cause self-study students, adopted the issue of pedagogy, symposia teaching methods, teaching methods, such as summarized compare teaching methods can improve English teaching results.

\section{References}

Lin, Lan. (2006). English Practice Teaching Model. Hunan Radio and TV University, (3).

Shao, Gang, Zhu, Ye \& Niu, Hui. (2004). Distance Education Theory and Practice of practical teaching. China Distance Education, (8).

Wang, Jiangen \& Zhang, Zhuying. (2004). Build a relatively complete system of practical teaching. China Distance Education, (2).

Zhao, Xia. (2006). Open Education English Teaching Online "Three Studies" model. China Distance Education, (7). 